\title{
Mapping the extent to which performance-based financing (PBF) programs reflect quality, informed choice and voluntarism and implications for family planning services: A review of indicators
}

Marie S. Cole

Victoria Boydell

Benjamin Bellows

Population Council

Karen Hardee

Follow this and additional works at: https://knowledgecommons.popcouncil.org/departments_sbsr-rh How does access to this work benefit you? Let us know!

\section{Recommended Citation}

Cole, Marie S., Victoria Boydell, Benjamin Bellows, and Karen Hardee. 2018. "Mapping the extent to which performance-based financing (PBF) programs reflect quality, informed choice and voluntarism and implications for family planning services: A review of indicators." Research report. Washington, DC: Population Council, The Evidence Project. 
Mapping the extent to which performance-based financing (PBF) programs reflect quality, informed choice and voluntarism and implications for family planning services A review of indicators

Victoria Boydell, University of Cambridge Marie S. Cole, PAI

Ben Bellows, Population Council

Karen Hardee, Hardee Associates 


\section{The Evidence Project}

Population Council

4301 Connecticut Avenue, NW, Suite 280

Washington, DC 20008 USA

tel +1202 2379400

evidenceproject.popcouncil.org

The Evidence Project is made possible by the generous support of the American people through the United States Agency for International Development (USAID) under the terms of cooperative agreement no. AID-OAA-A-13-00087.

The contents of this document are the sole responsibility of the Evidence Project and Population Council and do not necessarily reflect the views of USAID or the United States Government.

\section{Evidence}

The Evidence Project uses implementation science-the strategic generation, translation, and use of evidence - to strengthen and scale up family planning and reproductive health programs to reduce unintended pregnancies worldwide. The

Evidence Project is led by the Population Council in partnership with Population Reference Bureau.

Published in September 2018.

Suggested citation: Boydell, Victoria, Marie Cole, Ben Bellows, and Karen Hardee. 2018. "Mapping the extent to which performance-based financing $(\mathrm{PBF})$ programs reflect quality, informed choice, and voluntarism and implications for family planning services: A review of indicators," Research Report. Washington, DC:

Population Council, The Evidence Project.

Photo credit on cover page Jonathan Torgovnik

(C) 2018 The Population Council, Inc. 



\section{Table of Contents}

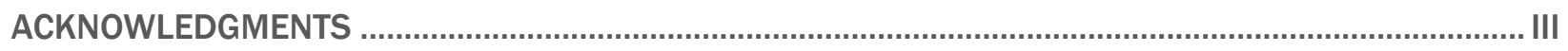

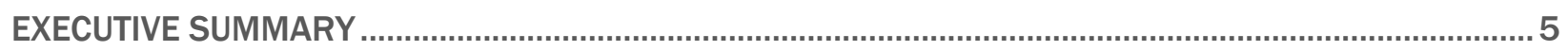

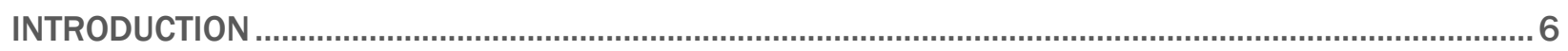

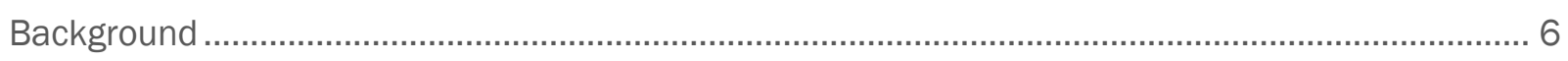

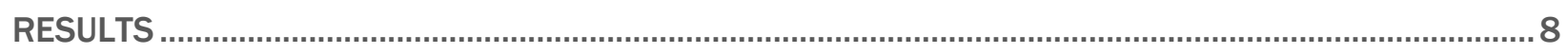

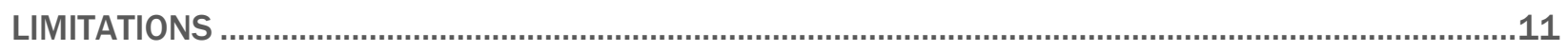

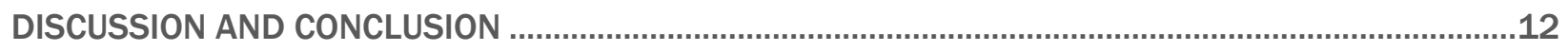

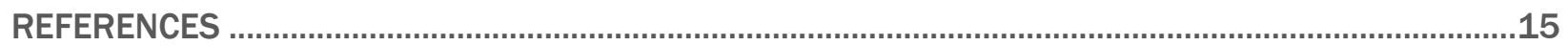

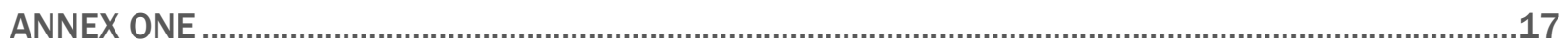




\section{Acknowledgments}

The authors of this report, Victoria Boydell, Marie Cole, Ben Bellows, and Karen Hardee, would like to acknowledge the insights from and engagement with members of communities of practice in family planning, rights, and results-based financing. From initial conversations to the documents review, the process opened up innovative perspectives on where alignment across these communities could produce a sum greater than the parts. Additionally, we would like to thank colleagues from the Evidence Project at the Population Council for facilitating the support for the study. Finally, we would like to thank Beverly Johnston, Division Chief, Bureau for Global Health, USAID; and the Evidence Project AORs Mihira Karra, Erika Martin, and Erika Houghtaling of USAID for their vision to see this through. 


\section{List of Acronyms}

$\begin{array}{ll}\text { CHW } & \text { Community Health Workers } \\ \text { FP } & \text { Family planning } \\ \text { GFF } & \text { Global Financing Facility } \\ \text { IUD } & \text { Intrauterine device } \\ \text { LARC } & \text { Long-acting reversible contraceptive } \\ \text { NSV } & \text { Nonscalpel vasectomy } \\ \text { PBF } & \text { Performance-based financing } \\ \text { RBA } & \text { Rights-based approach } \\ \text { RBF } & \text { Results-based financing } \\ \text { RMNCAH } & \text { Reproductive, maternal, newborn, child, and adolescent health } \\ \text { STI } & \text { Sexually transmitted infection } \\ \text { WHO } & \text { World Health Organization }\end{array}$




\section{Executive Summary}

Results-based financing (RBF) initiatives, which operate within the much larger financial and programming contexts of health systems, aim to expand coverage, improve quality and reduce consumer financial obligations at the country level in line with a nation's decision to progress toward universal health coverage. RBF programs have the potential to ensure that clients' needs for quality services are met through use of strategic incentives in health care provision and promoting more client-centered healthcare systems. Performance-based financing $(\mathrm{PBF})$ programs are considered a specific subset of RBF initiatives and are distinguished by a focus on monetary incentives to healthcare providers for achieving agreed performance measure under certain conditions. While both PBF, which uses financial disbursements to incentivize health service delivery and quality, and rights-based programming have informed at different times efforts to strengthen and scale FP services, there is has been little done to understand the linkages between PBF and a rights-based approach (RBA) to FP services. To address this gap, a review of PBF operations manuals was undertaken together with an analysis of PBF indicators relevant to FP services. This paper presents the results of the analysis of PBF indicators from country-sourced operational documents to determine the extent to which FP indicators are sensitive to the principles associated with an RBA.

The review catalogued FP indicators used in PBF programs and assessed their sensitivity to the rights principles. The relevant indicators were sources through 23 operational documents and 18 quality checks. We found 452 FP-related indicators, 57 were for quantity-based performance indicators and 395 questions were used to assess the quality of FP services. The majority of quantity-based performance indicators related to contraceptive service utilization. Fewer quantity-based indicators linked performance incentives to FP counselling, antenatal care, provision or referral by community health workers and one related to demand side incentive for FP counseling. The rights principles most often addressed are availability, quality, including privacy and confidentiality, and informed choice and acceptability and accountability were addressed to a lesser extent. There was no implicit link to the rights principles of accessibility, non-discrimination, and agency.

The review shows that existing PBF indicators capture some key elements of an RBA. For instance, aspects of quality and availability are extensively measured. Adapting existing measures could help to ensure existing indicators better align with an RBA. For example, informed choice is tracked in several PBF programs now but with further adoption and adaptation of the method information index and related counseling quality indicators, it is reasonable to expect a greater alignment of PBF with rights principles. Despite the opportunity for greater integration, there are challenges inherent in measuring some dimensions of an RBA, particularly related to client-provider interactions, service users' experience and engagement. For instance, agency and accessibility require information from the consumer perspective that is not easily observed by third parties 


\section{Introduction}

\section{BACKGROUND}

Results-based financing $(\mathrm{RBF})$ initiatives, which operate within the much larger financial and programming contexts of health systems, aim to expand coverage, improve quality and reduce consumer financial obligations at the country level in line with a nation's decision to progress toward universal health coverage (Kutzin 2013; Wagstaff, et al. 2015). Performance-based financing (PBF) programs are considered a specific subset of RBF initiatives and are distinguished by a focus on monetary incentives to healthcare providers for achieving agreed performance measure under certain conditions.

Expanding access to and use of voluntary family planning (FP) services is a global health goal, including under EWEC, FP2020, and the Sustainable Development Goals (Every Woman Every Child 2016; Family Planning 2020 2017; United Nations n.d.). Strengthening PBF programming to increase equitable access to high quality, informed, voluntary family planning (FP) is a promising approach to achieve global FP goals.

FP2020, the global partnership to achieve the ambitious goal of having an additional 120 million voluntary FP users by 2020, supports and encourages rights-based programming to ensure that individuals and couples can freely decide the number and spacing of their children, with quality FP information and services to do so, and without facing discrimination and inequality (Family Planning 2020, 2018). There is increasing consensus that the principles imperative for voluntary FP are acceptability; accessibility; availability; and quality (recognized as AAAQ); as well as (a) accountability; (b) agency, autonomy and empowerment; (c) equity and nondiscrimination; (d) informed choice and informed decision-making; (e)participation; and (f) privacy and confidentiality (Family Planning 2020 2014; WHO 2014; UNCESCR 2000), see text box. Unique dimensions of voluntarism are found among these different principles as well (Kumur, et al. 2017; Hardee, Harris, et al. 2014). PBF programs have the potential to ensure that clients' needs for quality services are met through use of strategic incentives in health care provision and promoting more client-centered healthcare systems.

\section{What is performance-based financing?}

PBF is a health financing instrument through which payments to healthcare providers are made for health services conditional on performance on predefined and verified quantity indicators, adjusted for measures of quality.

\section{What is a rights-based approach to family planning?}

An RBA to family planning applies a set of standards enabling individuals and couples to decide freely and responsibly the number and spacing of their children, to have the information and services to do so, and to be treated equitably and free of discrimination.

While both PBF, which uses financial disbursements to incentivize certain behaviors and/or services, and an RBA are essential components of current FP programs, limited assessments have been done to understand the linkages between PBF and an RBA. This paper explores the role and characteristics of PBF indicators for FP services as a companion to Cole et al. 2018, which reviews PBF operational manuals. Together, these papers map the extent to which FP services in PBF programs reflect a rights-based approach. 


\section{Purpose}

Given the potential benefits of PBF to expand access to and improve the quality of FP services, as well as the potential risks for violating RBA principles, this paper reviews country-generated PBF operational documents to assess whether existing FP indicators are sensitive to the principles associated with an RBA. It focuses on the current state of quantity-based performance and quality of care indicators specific to FP services within PBF programs.

Many PBF programs pay for the delivery of a combination of quantity and quality performance indicators. Both service delivery indicators (e.g., number of new users) and quality of care measures (e.g., content of clinical care) are incentivized. In addition, a quality of care score (often generated via a checklist) is used to assess performance, and this score then modifies the quantity-based disbursement. When quantity-based performance indicators are achieved and verified, the funding disbursement is triggered. These payments are often made to a health care team (e.g. a health facility) or an administrative unit (e.g. a district health office) based on service-related or facility-related factors, not linked to a specific staff member's performance.

The World Bank and other partners have made extensive use of PBF to deliver FP services among a range of other strategies and many countries supported by the GFF are expanding PBF. Though this review includes documents that pre-date the GFF, we make several recommendations to ensure that rights are central to the discussions taking place between governments, multilateral development agencies, and donors. These lessons about an RBA in the context of PBF also generalize to other strategic purchasing approaches including development impact bonds, program for results loans, performance contracting, as well as national and social insurance schemes.

\section{Methods}

The review catalogued FP indicators used in PBF programs and assessed their sensitivity to the rights principles listed above. Definitions of these principles are found in Cole et al. 2018. Two different data sources were used to identify the relevant indicators. The first were 23 operational documents sourced through web searches and expert consultations. The second source is 18 quality checks identified through the "Multi-Country Performance Based Incentives Quality Checklist Database," developed by ThinkWell (TRAction Project 2016).

From a web search and consultations with PBF and FP experts, 23 relevant operational documents (one each from 23 countries) in either English or French were identified for full review. All of the documents are the most recent versions of operational or implementation manuals that were publicly available during the 2017 review. Each was reviewed for all quantity-based FP performance indicators and a total of 59 indicators were found. Indicators that were the same across several countries were grouped together and then these were assessed to see if they had an explicit or implicit link to any of the rights principles.

We also compiled the questions used to assess the quality of FP services from the database developed by ThinkWell (TRAction Project 2016). From 18 national quality checklists, we extracted and assessed a total of 395 questions that are used to assess quality. The same questions across countries were grouped together and then assessed for an explicit or implicit link to any of the rights principles. 


\section{Results}

In this review, we found 452 FP-related indicators, 57 were for quantity-based performance indicators and 395 questions were used to assess the quality of FP services.

\section{Quantity-based performance indicators for FP}

The 57 quantity-based performance indicators for FP in the 23 PBF manuals are listed in Annex 1. Once checked for content and duplication, we consolidated the indicators in Table 1 and noted the number of manuals in which each indicator appears.

Table 1: Quantity-based performance indicators in 23 national PBF operational manuals.

\begin{tabular}{|c|c|}
\hline Indicator & $\begin{array}{l}\text { Number of } \\
\text { operations manuals }\end{array}$ \\
\hline $\begin{array}{l}\text { Number of new and continuing users for short acting methods (pills or } \\
\text { injectables) }\end{array}$ & 12 \\
\hline $\begin{array}{l}\text { Number of new and continuing users of long acting methods (intrauterine } \\
\text { device [IUD] and implants) }\end{array}$ & 12 \\
\hline Number of new users for long acting methods (IUDs and Implants) & 8 \\
\hline Number of tubal ligation and vasectomy performed & 6 \\
\hline Number of users for modern FP & 5 \\
\hline Number of clients counseled for FP & 4 \\
\hline Number of new users of modern FP & 3 \\
\hline $\begin{array}{l}\text { Percent of women aged } 30-60 \text { having counseling on early detection of sexually } \\
\text { transmitted infections STI), female cancers, FP, and preconception care. }\end{array}$ & 1 \\
\hline $\begin{array}{l}\text { Number of eligible puerperal women who received counselling on sexual and } \\
\text { reproductive health within } 45 \text { days after childbirth }\end{array}$ & 1 \\
\hline Number of new users for short acting methods (pills \& injectables) & 1 \\
\hline 3 home visits for antenatal care include FP counselling & 1 \\
\hline $\begin{array}{l}\text { Couple-years protection (CYP) provided by facilities and community health } \\
\text { volunteers (disaggregated by method) }\end{array}$ & 1 \\
\hline $\begin{array}{l}\text { Percent of women referred for FP by community health workers (CHW) to health } \\
\text { center (any method) }\end{array}$ & 1 \\
\hline $\begin{array}{l}\text { Proportion of married, non-pregnant women of reproductive age who or whose } \\
\text { partner are currently using at least } 1 \text { FP method (household survey) - } \\
\text { Contraceptive prevalence rate (CPR) }\end{array}$ & 1 \\
\hline $\begin{array}{l}\text { Number of eligible puerperal women who received counselling on sexual and } \\
\text { reproductive health within } 45 \text { days after childbirth }\end{array}$ & 1 \\
\hline
\end{tabular}

Most indicators were applied at the health facility or dispensary level. Few were measured at a hospital level. The indicator capturing number of tubal ligations and vasectomies was relevant for higher level health facilities. The majority of indicators ( $\mathrm{n}=42$ out of the 57$)$ related to contraceptive service utilization. However, nine indicators linked performance incentives to FP counselling. The inclusion of FP as part of antenatal care ( $n=1$ of 57 ), provision or referral by community health workers ( $n=1$ of 57 ) and one related to demand side incentive for FP counseling ( $\mathrm{n}=1$ of 57 ) were less common measures of performance. 
Often a distinction was made between a minimum package of care for lower tier primary care facilities and a comprehensive package of care for higher level facilities, which often included the addition of the provision of permanent methods. Interestingly, the Democratic Republic of the Congo (DRC) manual did not incentivize permanent methods even though it was part of its comprehensive package of care.

\section{Quality indicators for FP-related services in the PBF program manuals}

Out of the 395 questions related to assessing the quality of FP, 18 were extracted from country quality checklists. The rights principles most often addressed are availability $(\mathrm{n}=193)$, quality, including privacy and confidentiality $(\mathrm{n}=128)$, and informed choice $(\mathrm{n}=51)$. Less addressed principles were acceptability $(\mathrm{n}=4)$ and accountability $(\mathrm{n}=2)$. There was no implicit link to the rights principles of accessibility, nondiscrimination, and agency. The questions were assessed for duplications and then compiled into groupings per rights/rights principle, shown in Table 2.

Table 2: Questions in the quality checklist related to quality of FP grouped by rights principles

\begin{tabular}{|c|c|}
\hline $\begin{array}{l}\text { Rights/Rights } \\
\text { Principle }\end{array}$ & Questions currently used to capture (total out of 396 questions) \\
\hline Acceptability & $\begin{array}{l}\text { Information Education Communication / Behavior Change Communication (IEC / BCC) } \\
\text { group: (1) Group chat conducted before the consultation session and (2) Existence of a list } \\
\text { of IEC updates related to (a) Theme, (b) Number of participants, (c) Activity manager, (d) } \\
\text { Date, and (e) Signed ( } n=4 \text { of } 395 \text { questions) }\end{array}$ \\
\hline $\begin{array}{l}\text { Accountability/ } \\
\text { Participation/ } \\
\text { Transparency }\end{array}$ & Presence of Complaints Box; complaints stored $(n=2)$ \\
\hline $\begin{array}{l}\text { Agency/Autonomy/ } \\
\text { Empowerment/ } \\
\text { Voluntarism }\end{array}$ & N/A \\
\hline \multirow{5}{*}{ Availability } & Availability of specific methods (e.g. IUD, implants, injectables, condoms) ( $n=103$ ) \\
\hline & Staff available to provide specific methods (e.g. IUD, implants) $(n=32)$ \\
\hline & Range of contraceptive commodities available $(n=17)$ \\
\hline & Staff trained in FP $(n=17)$ \\
\hline & Equipment available $(n=23)$ \\
\hline \multirow{3}{*}{ Informed choice } & Display of Client Rights $(n=2)$ \\
\hline & Availability of wall posters or box to demonstrate FP methods $(n=39)$ \\
\hline & Conduct exit interview about informed choice of FP methods $(n=10)$ \\
\hline $\begin{array}{l}\text { Non-discrimination/ } \\
\text { Equity }\end{array}$ & NA \\
\hline \multirow{10}{*}{ Quality } & Consultation by qualified staff $(n=4)$ (technical competency) \\
\hline & $\begin{array}{l}\text { Justification of recommendation method documented in patient records (technical } \\
\text { competency) }(n=13)\end{array}$ \\
\hline & $\begin{array}{l}\text { Complete FP consultation with justification of method, history, questions and examination } \\
\text { complete (technical competency) }(n=6)\end{array}$ \\
\hline & Adequacy of method chosen $(n=1)$ \\
\hline & Advantages and disadvantages of methods know (technical competency) ( $n=1)$ \\
\hline & $\begin{array}{l}\text { FP register available and completed (Offering a range of services and continuity of care) } \\
(\mathrm{n}=18)\end{array}$ \\
\hline & $\begin{array}{l}\text { FP record/cards filled correctly (Sample) (Offering a range of services and continuity of care) } \\
(n=21)\end{array}$ \\
\hline & $\begin{array}{l}\text { Staff correctly calculates the number of women expected every month for FP method(s) } \\
\text { (Offering a range of services and continuity of care) }(n=22)\end{array}$ \\
\hline & $\begin{array}{l}\text { Staff correctly calculates the number of women expected every month for specific FP } \\
\text { method (Offering a range of services and continuity of care }(n=16)\end{array}$ \\
\hline & $\begin{array}{l}\text { Presence of FP flowcharts and job aids (Offering a range of services and continuity of care) } \\
(n=1)\end{array}$ \\
\hline
\end{tabular}




\begin{tabular}{l}
\hline Control and monitoring (meeting established) (follow-up) $(n=1)$ \\
\hline Appointments made for follow-up (follow-up) $(n=3)$ \\
\hline Check if follow-up was undertaken (follow-up) $(n=1)$ \\
\hline Follow-up visits with FP side-effect and discontinuation (follow-up) $(n=1)$ \\
\hline Strategy in place for couples seeking permanent methods (referrals) $(n=7)$ \\
Privacy ensured in consultation room (e.g. curtains on windows, no transparent glass, no \\
through passage, closed door) ( $n=24)$
\end{tabular}

The majority of the questions assessed availability $(n=192)$ and quality, including privacy and confidentiality $(n=128)$. With the principle of availability, most questions related to the availability of specific methods. Under the principle of quality, most questions pertained to offering a range of services and continuity of care (e.g. completion of FP records, availability of the FP register and staff ability to correctly forecast the number of women expected every month for a specific FP method).

Fifty-one questions linked to informed choice, the majority related to the provision of information about FP and a few related to sharing information about client rights. Ten questions captured informed choice through client exit interviews, the same questions were asked from a quality checklist taken at different levels in Tanzania.

The majority of questions in the quality checklists measure more tangible material items that can be physically counted and assessed (records, display materials, stocks in place). Only one question obtains information from the provider and one set of questions assessed users' perspectives (10 client exit interview questions on informed choice).

The means of assessment were patient records $(n=44)$, checklists $(n=295)$, registers $(n=210)$, register review $(\mathrm{n}=45)$, and one from staff interviews. 


\section{Limitations}

This report was limited to the review of indicators found in the country-specific operations or implementation manuals for PBF programs sourced through web searches, expert consultations and the ThinkWell database of quality checklists. It does not include a review of all existing PBF operations or implementation manuals and checklists, including some developed by non-governmental organizations that may use different indicators. Nor does the study assess the size of payments relative to the effort to achieve any included indicator. The value of a provider's effort or the size of the incentive to induce a change in provider behavior was beyond the scope of this review.

In addition, the indicators were taken from the most recent documentation available and set against normative standards and do not provide an assessment of how programs have evolved to advance or limit rights over time. As an RBA is not required as part of PBF, our matching of an RBA with PBF indicators does not reflect whether or not there have been interventions to improve an RBA.

Finally, information on pricing and values was not consistently included in the manuals. There was limited information on prices paid for meeting quantitative or qualitative indicators or the significance of these prices, which would be useful to compare the values of indicator payments by country. In addition, there was limited detail on how subsidies are distributed at the facility level. There were unknowns on whether incentives were paid as bonuses or as operational costs and whether quality adjustments were calculated as a bonus (positive) or deduction (negative). 


\section{Discussion and Conclusion}

This review was undertaken to determine the extent to which PBF indicators linked to FP services and incorporated an RBA. The review shows that existing PBF indicators capture some key elements of an RBA. For instance, aspects of quality and availability are extensively measured. Adapting existing measures could help to ensure existing indicators better align with an RBA. For example, informed choice is tracked in several PBF programs now but with further adoption and adaptation of the method information index and related counseling quality indicators, it is reasonable to expect a greater alignment of PBF with rights principles. Despite the opportunity for greater integration, there are challenges inherent in measuring some dimensions of an RBA, particularly related to service users' experience and engagement. For instance, agency and accessibility require information from the consumer perspective that is not easily observed by third parties.

Quantity-based performance indicators for FP services typically counted the number of client visits or the number of FP acceptors. Numbers of new acceptors and/or repeat users of modern contraceptives, percentage of women of childbearing age using any modern FP method, and increasing the contraceptive prevalence rate are all measures of FP service delivery that may reflect accessibility, availability, acceptability, and many other rights principles. Many of these indicators measure the number of FP users or new users. New user measures have been critiqued, in that they can have multiple definitions including first-time user, new to the provider (e.g., provider-changer), new to the method (e.g., switching methods), not recently using a method (e.g., lapsed user), and even additional user (Dasgupta et al. 2017). Focusing on the number of new users of modern contraceptives has been associated with trends in skewed method mix, provider bias, or commodity stock-outs that may reflect users having limited information and fewer options (RamaRao and Jain 2015). In addition, many of these indicators measure the number of new and/or continuing users of a specific FP method. The focus on the distribution by method often links to a higher-level impact measure based on the relative effectiveness of specific methods or a desire to remove contraceptive price as a barrier to consumer choice.

The lack of specification around who are using the services causes confusion for purposes of deciding whether and how PBF programs are adhering to RBAs to FP and providing quality care, informed choice and voluntarism for clients. An RBA would ideally focus on disaggregating the number of new or continuing users by social factors (age, income, gender, and so on) to better understand issues of equitable access and discrimination (Gruskin et al. 2017). Disaggregating the information by (a) age, (b) income, (c) residency, and (d) education would better help determine who these services are reaching and conversely who may be underserved. Being mindful of limitations of the routine data systems, indicators tracking adolescents and postpartum women counselled are examples of indicators currently measuring disparities.

Moreover, attempts at measuring non-discrimination and equity are reflected in the larger PBF programs, which have a wider set of service output indicators as well as administrative indicators about the functioning of the program itself. Where program elements do not lend themselves to facility-based measurement, they could be operationalized using other methodologies at different levels of the health system. These wider PBF indicators may be sensitive to elements of an RBA and should also be taken into consideration. For instance, several PBF program documents detail how equity is incentivized with 'equity bonuses' (e.g. Afghanistan, Mozambique, Burkina Faso, Cameroon) or incentivized reaching specific underserved populations, such as indigenous or indigent populations. There are also measures and incentives for service provision in remote health centers (e.g. Zambia). In addition to the service performance indicators, there are a set of administrative indicators, usually at local health offices and above, related to the performance of program activities (e.g. regular reporting, budgeting, planning) as part of the program's own internal accountability systems. In Cameroon, the percentage of facilities with a health committee meeting three times in a quarter is 
also incentivized and an important means of measuring participation and accountability. These wider PBF programs have elements that could be built upon.

The quantity-based performance indicators for FP services that focus on contraceptive service utilization do not capture the nature or content of the client-provider interaction nor issues of access that are more aligned with an RBA (RamaRao and Jain 2015). With a focus on measuring service use, we do not know if users were given full information and had a full range of options to choose from. We would anticipate this to be captured in the quality indicators, yet these mostly focus on specific methods being available rather than the quality of counselling or information shared. Several PBF programs measure the number of users counselled: this measure is more conducive to an RBA as the emphasis is on the provision of information and the interaction with the users so as to support them to make full, free and informed choice about the contraceptive method best for them.

The principle of informed choice was explicitly mentioned in Tanzania's quality checklist and other quality indicators in that checklist had implicit links to rights principles, such as availability and quality. Yet what is currently captured within and measured by the quality indicators linked to FP services tends to be more easily observable and amenable for collection and verification by health service actors. Most of the information is assessed using patient records and registers and counts the instances of services rather than the content and quality of the services. For example, the numbers of commodities available is a common indicator. While such dimensions are a critical part of quality FP services and potentially link to several rights principles, programs pay less attention to rights in their entirety and often miss the most important factor in an RBA to health: the health care user. In the indicators identified in this review, there was no implicit link to the principles of accessibility, non-discrimination, voluntarism, agency, and participation. None of the questions examined inequalities or barriers faced by specific populations. There was little on the quality or the content of the client-provider interaction.

Though it is generally agreed that measuring and tracking quality is critical to improving service delivery and health outcomes, there are no standardized or accepted tools to assess the quality of FP services (Sprockett 2017). This trend is not unique to quality checklists in PBF programs but is characteristic of assessing quality of FP more broadly and reflects a broader data challenge in quality and FP. Most existing measures currently assess the structural aspects of quality over the process dimensions as the structural aspects are relatively easy and inexpensive to measure, but only establish a minimum level of quality rather than the level of performance (Sprockett 2017). Quality, therefore, is a supply-side concern yet patients' own assessments of quality, the demand side, are central to how they use services and consequently to health outcomes (Akachi and Kruk 2017). Therefore, only by directly understanding patients' experiences can we learn what is and is not working in terms of quality of care (Akachi and Kruk 2017). There are several efforts underway to measure patients' experience of quality of care for FP services that hold much promise for inclusion in existing quality measurements (Holt et al. 2017; Sudhinaraset et al. 2017).

In both the quality and quantity assessments of FP in PBF programs there is a strong focus on methods, such as the number of users by methods or methods available. This could reflect a desire to increase the number of options available for users to choose, particularly those that are less available (e.g. long-acting reversible contraceptives [LARC]). It may also reflect a focus on the uptake of specific methods over others. PBF measures, therefore, need to move beyond service provision and method uptake to include both client's experiences as well as their interactions with providers. In addition, a noticeable gap was the absence of a performance metric for LARC removals. Women seeking to space births may be reluctant to consider taking up the IUD or implant without clear assurances that removal services are readily available. Performance metrics that track LARC removals would speak to breadth of service availability and facility quality. 
The majority of quantity and quality indicators found in this review are commonly used in FP (see Measure Evaluation 2017). Recent assessments of the sensitivity of commonly used FP indicators to an RBA found limited explicit reference to RBA principles and many dimensions of an RBA were absent (Wright and Hardee 2015; Gruskin et al. 2017). Given the complex nature of RBAs, no one indicator could capture all the dimension of rights and several indicators are required. Indicators for certain dimensions of an RBA are well developed and established or could be slightly adapted to ensure they better align with an RBA such as specifying who they are reaching. Yet some dimensions of an RBA, namely non-discrimination, voluntarism, and agency, are less commonly captured in the field of FP or more difficult to quantify as they are subjective in nature. These measures require investment for development and advocacy for adoption.

GFF principles and the direction of World Bank financing are increasingly moving to improve accountability, shifting focus to results, and giving countries the lead to define process. Defining RBAs in measurable terms will accelerate the systematic uptake of RBA principles into GFF and International Development Association financed projects.

Finally, PBF programs are working within an existing health system, responding to existing routine data and indicators, and deficiencies reflect a broader data challenge for FP services and rights-based programming. Many PBF programs draw from existing data sources and indicators. A consideration of an PBF program's alignment with RBA principles should be done in light of the status quo found in that national FP program and health system. Governments are increasingly going to use routine data to make resource allocation decisions. There are better and worse ways to do this, and for rights to be part of that purchasing discussion, practical scalable approaches will need to be identified. There is an opportunity and need for research to test approaches and build the evidence base to close this policy gap. 


\section{References}

Akachi, Y., and Kruk, M. (2017). "Quality of care: measuring a neglected driver of improved health," Bulletin of the World Health Organization. 95:465-472 | doi:http://dx.doi.org/10.2471/BLT.16.180190

Cole, M. et al., 2018. Mapping the Extent to Which Results-Based Financing Programs Reflect Quality, Informed Choice and Voluntarism and Implications for Family Planning Services: A review of RBF operational manuals, Washington, DC: Population Council, The Evidence Project.

Dasgupta A, et al. (2017). ““““New users” are confusing our counting: reaching consensus on how to measure "additional users" of family planning," Global Health Science and Practice. 5(1):6-14.

Every Woman Every Child. (2016). Every Woman Every Child: About. Retrieved January 2, 2018, from http://www.everywomaneverychild.org/about/\#sect5

Family Planning 2020. (2014). Family Planning 2020: Rights and Empowerment Principles for Family Planning. Retrieved from http://www.familyplanning2020.org/resources/4697

Family Planning 2020. (2017). About Us. Retrieved December 5, 2017, from http://www.familyplanning2020.org/microsite/about-us

Family Planning 2020. (2018). Rights-Based Family Planning. Retrieved December 31, 2017, from http://www.familyplanning2020.org/microsite/rightsinfp

Gruskin S, et al. (2017) "A novel methodology for strengthening human rights based monitoring in public health: Family planning indicators as an illustrative example," PLoS ONE 12(12): e0186330. https://doi.org/10.1371/journal.pone.0186330

Hardee, K., Harris, S. et al., (2014). “Achieving FP2020 Goal through Voluntary, Rights-based Family Planning: What Can We Learn from Past Experiences with Coercion?” International Perspectives on Sexual and Reproductive Health, 40(4), 206-214.

Hardee, K., Kumar, J. et al., (2014). "Voluntary, Human Rights-based Family Planning: A Conceptual Framework," Studies in Family Planning, 45(1), 1-18.

Harris, S. Reichenbach, L. and Hardee, K., (2006). "Measuring and monitoring quality of care in family planning: are we ignoring negative experiences?” Open Access Journal of Contraception. 7, 97-108

Holt K, Dehlendorf C, and Langer A. "Defining quality in contraceptive counseling to improve measurement of individuals' experiences and enable service delivery improvement," Contraception. 2017 09; 96(3):133137. PMID: 28645986

Jain A, Hardee K. "Revising the FP Quality of Care framework in the context of Rights-based Family Planning," Studies in Family Planning 2018; 49(2):171-179.

https://onlinelibrary.wiley.com/doi/epdf/10.1111/sifp.12052.

Kumur, J. et al., (2017). Rights-Sizing Family Planning: A Toolkit for Designing Programs to Respect, Protect and Fulfill the Rights of Girls and Women. Retrieved from http://ec2-54-210-230-186.compute1.amazonaws.com/wp-content/uploads/2017/05/DRAFT_FP2020_Rights-Sizing-Family-Planning- 
Toolkit.pdf

Kutzin, J. (2013). "Health financing for universal coverage and health system performance: Concepts and implications for policy," Bulletin of the World Health Organization, 91 (November 2012), 602-611. https://doi.org/10.2471/BLT.12.113985

Measure Evaluation (2017) Family Planning and Reproductive Health (FP/RH) Indicators Database https://www.measureevaluation.org/prh/rh_indicators/overview

Measure Evaluation. 2018. Results-Based Financing Indicator Compendium for RMNCAH Initiatives. Chapel Hill, North Carolina, USA; 2018. https://www.measureevaluation.org/rbf. Accessed August 22, 2018.

RamaRao, S. and Jain, A. K. (2015), "Aligning Goals, Intents, and Performance Indicators in Family Planning Service Delivery," Studies in Family Planning, 46: 97-104. doi:10.1111/j.1728-4465.2015.00017.x

Sudhinaraset M, and Afulani P, Diamond-Smith $\mathrm{N}$ et al. "Advancing a conceptual model to improve maternal health quality: The Person-Centered Care Framework for Reproductive Health Equity," [version 1; referees: 2 approved, 2 approved with reservations]. Gates Open Res 2017, 1:1 (doi: $10.12688 /$ gatesopenres.12756.1)

Sprockett, A. (2017) "Review of quality assessment tools for family planning programmes in low- and middleincome countries," Health Policy and Planning, 32, 2017, 292-302 doi: 10.1093/heapol/czw123

TRAction Project. 2016. "Multi-Country Performance Based Incentives Quality Checklist Database.” Available at: http://www.tractionproject.org/resources/results-based-management-performance-based-incentivesquality-care/multi-country

UN CESCR. (2000). CESCR General Comment No. 14: The Right to the Highest Attainable Standard of Health (Art. 12).

United Nations. (n.d.). Goal 3: Ensure healthy lives and promote well-being for all at all ages. Retrieved December 5, 2017, from http://www.un.org/sustainabledevelopment/health/

United Nations Population Fund. (2014). Programme of Action of the International Conference on Population Development. 20th Anniversary Edition.

Wagstaff, A. et al. (2015). Measuring Progress Towards Universal Health Coverage With An Application to 24 Developing Countries (Policy Research Working Paper No. No. 7470). Washington D.C.

WHO. (2014). Ensuring human rights in the provision of contraceptive information and services - Guidance and recommendations. World Health Organization. Geneva. https://doi.org/10.1109/ITAB.2007.4407404

WHO (2017). Monitoring human rights in contraceptive services and programmes. Geneva: License: CC BY-NC-SA 3.0 IGO. http://apps.who.int/iris/bitstream/10665/259274/1/9789241513036-eng.pdf

Wright, K. and Hardee, K. (2015) Proposed Indicators to Measure Adherence to and Effects of Rights-Based Family Planning: Resource Guide. Washington, DC: Population Council, The Evidence Project. 


\title{
Annex One
}

Table 3: Full list of quantity-based performance indicators for FP in PBF programs found in 23 operational manuals.

\begin{abstract}
Afghanistan
Contraceptive prevalence rate (CPR) - Proportion of married, non-pregnant women of reproductive age who or whose partner are currently using at least $1 \mathrm{FP}$ method (household survey)

Argentina

Number of eligible puerperal women who received counselling on sexual and reproductive health within 45 days after childbirth / Number of eligible puerperal women (provincial level)
\end{abstract}

\section{Armenia}

Counselling on reproductive health and FP: percent of women aged 30-60 having counselling on early detection of STIs, on female reproductive system cancer dangers and signs, on FP and preconception care. (PHC facility level)

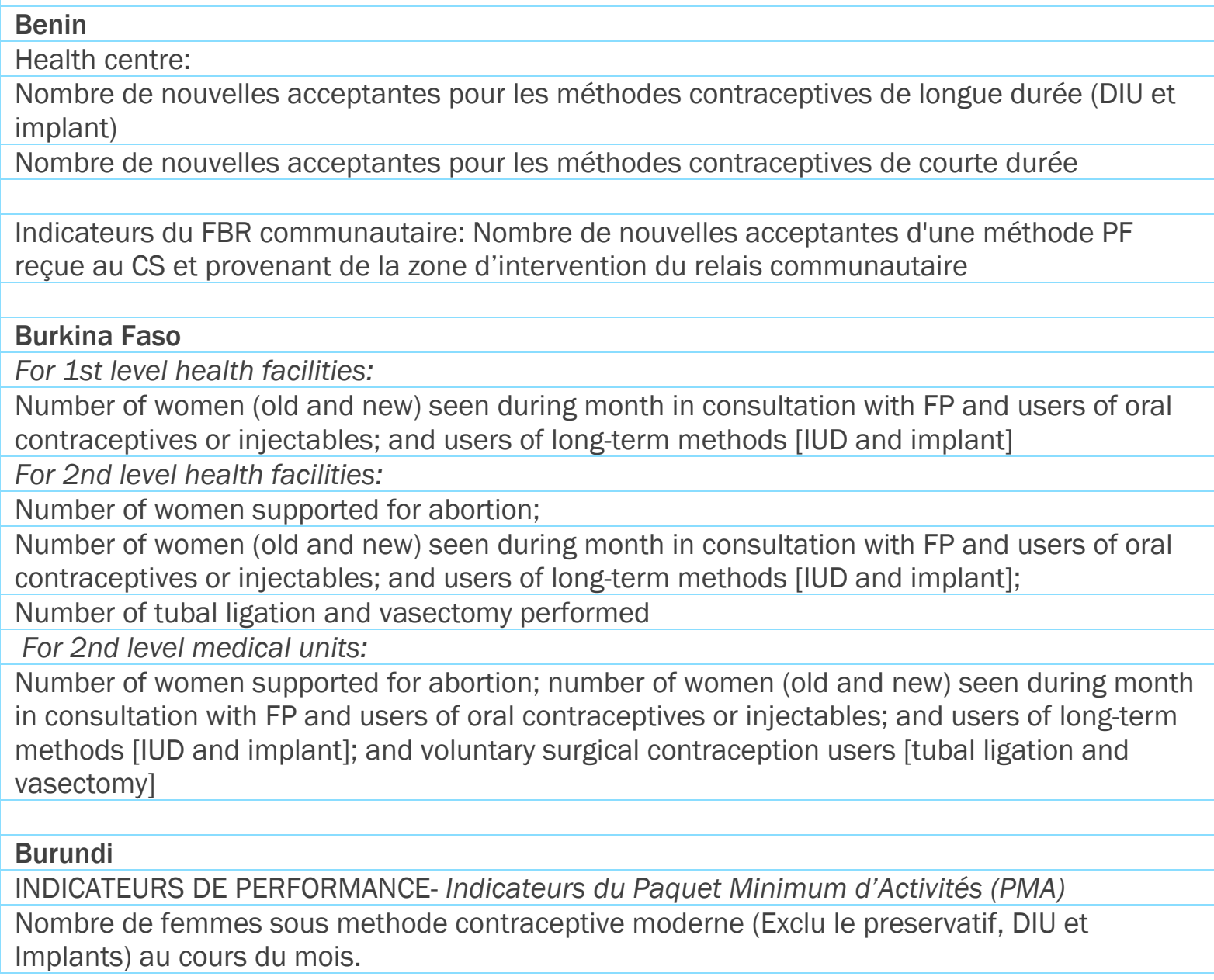


Nombre de femmes chez qui le DIU ou l'implant ont ete poses au cours du mois comme methode contraceptive moderne choisie.

Indicateurs du Paquet Complémentaire d'Activités (PCA)

Nombre de femmes chez qui le DIU ou l'implant ont ete poses au cours du mois comme methode contraceptive modern choisie.

Nombre de femmes sous methode contraceptive modern (Exclu le preservatif, DIU et Implants) au cours du mois.

Nombre de personnes ayant beneficie de vasectomie ou ligature des trompes comme methode contraceptive au cours du mois.

\section{Cameroon}

Output Indicators for the Minimum Package of Health - Health Center

Total number of both old and new acceptants of FP who are currently on oral pills or injections

Number of new cases of implants and/or IUD carried out in the month

\section{Djibouti}

Indicateurs de rétribution au niveau du poste de santé (PMA)

Nouvelles acceptrices et utilisatrices continues de méthodes modernes de longue durée de planning familiale (injectables, DIU, implants) prescrites dans le système publique Indicateurs de rétribution au niveau du Centre Médical Hospitalier (CMH) (paquet complémentaire d'activités, PCA, au niveau des Régions)

Nouvelles acceptrices et utilisatrices continues de méthodes modernes de longue durée de planning familiale (injectables, DIU, implants) prescrites dans le système publique Indicateurs de rétribution au niveau du Centre de santé communautaire (CSC) (PCA au niveau de la ville).

Nouvelles acceptrices et utilisatrices continues de méthodes modernes de longue durée de planning familiale (injectables, DIU, implants) prescrites dans le système publique

Chad

No documents

Congo

No documents

\section{DRC (PM available not incentivized)}

Le paquet minimum de services de santé (PMA) et leurs barèmes

PF: Acceptantes nouvelles et renouvellment (oral \& inj)

PF: Acceptantes nouvelles et renouvellment (DIU et implant)

\section{The Gambia}

only checklist

\section{Ghana}

only TOR

\section{Haiti}

Indicateurs Quantitatifs du PES- Centre de Santé pour le

Nombre de clients utilisant une méthode modern de PF 
Kenya

Health facilities

Number of women of reproductive age (WRA) 15 -49 years who have received short acting FP commodities for the first time

Number of women of reproductive age (WRA) 15 -49 years who have received long acting FP commodities for the first time

\section{Kyrgyz Republic \\ No document}

\section{Ivory Coast}

Indicateurs retenus PMA

Femme utilisatrices de contraceptifs oraux ou d'injectables - anciennes et nouvelles

Femmes utilisatrices de méthodes de longue durée (DIU et implant) - anciennes et nouvelles

1er, 2ème, 3ème visite à la domicile selon protocole: (évacuation de déchets, latrine ou

toilette propre, moustiquaire dispo, accès à l'eau propre, utilisation PF, et vaccination)

Indicateurs retenus PCA - hôpitaux

Nombre de femmes (anciennes et nouvelles) en consultation et utilisatrices contraceptifs oraux ou d'injectables

Femmes (anciennes et nouvelles) utilisatrices de méthodes de longue durée (DIU et implant)

Femme ou homme utilisateurs ligature des trompes et vasectomie

\section{Lesotho}

Minimum Package of Activities (MPA): Services to be incentivized at the health centre level with relative weights and unit

Number of new and repeat users of short-term modern contraceptive methods Women receiving intrauterine device and Implants for the first time or are repeat users. Each of the method provides an estimated protection for 3 or more years.

Complementary Package of Activities (CPA): Services to be incentivized at the district/local hospital level with relative weights and unit fees

Number of new and repeat users of long-term modern contraceptive methods

Liberia
Facility levels
Couple-years of contraceptive protection (CYP) provided by supported facilities and community
health volunteers (CHV) (disaggregated by method)

\section{Malawi}

Facility levels

Number of clients counseled for FP

\section{Mali}

Au niveau CSCOM (Centre de Santé niveau primaire)

Nombre de femmes sous planification familiale modern

\section{Nigeria}

Minimum package of care-

New and existing users of injectables or oral contraceptives in the last month

New users of implants and IUDs in the last month 
Comprehensive package of care-

New and existing users of injectables or oral contraceptives in the last month

New users of implants and IUDs in the last month

New users of vasectomies and bilateral tubal ligation in the last month

\section{Rwanda}

CHW

Percentage of women referred for FP by CHWs to health center (any method),

Percentage of women (21-45 years) who initiate long term FP users (IUD, Norplant, surgical/ nonscalpel vasectomy [NSV] contraception).

In-kind incentives for women

Increase the number of women 21-49 years who initiate long-term modern contraceptives

(IUD, Norplant, surgical/NSV contraception) from $27 \%$ to $40 \%$

\section{Senegal}

Quality tools only

\section{Sierra Leone}

Facility level

Women of reproductive age using modern FP methods for protection against unwanted pregnancy monthly (BPEHS 7.2)

\section{Tajikistan}

Number of women 15-49 using modern contraceptives at the end of the month

\section{Tanzania}

Quantity indicators for health centers and dispensaries

Number of new users on modern FP methods

\section{Zambia}

Facility level new FP acceptors

\section{Zimbabwe}

Facility

Number of women 15-49 years receiving during their first and repeat visits one of FP long acting reversible methods (IUCDs, implants)

Number of women 15-49 years receiving during their first and repeat visits one of FP shortterm modern methods (progesterone only pill, oral contraceptive pill and Depo-Provera) Hospitals

Number of women 15-49 years who underwent a tubal ligation; Number of men who underwent vasectomy 


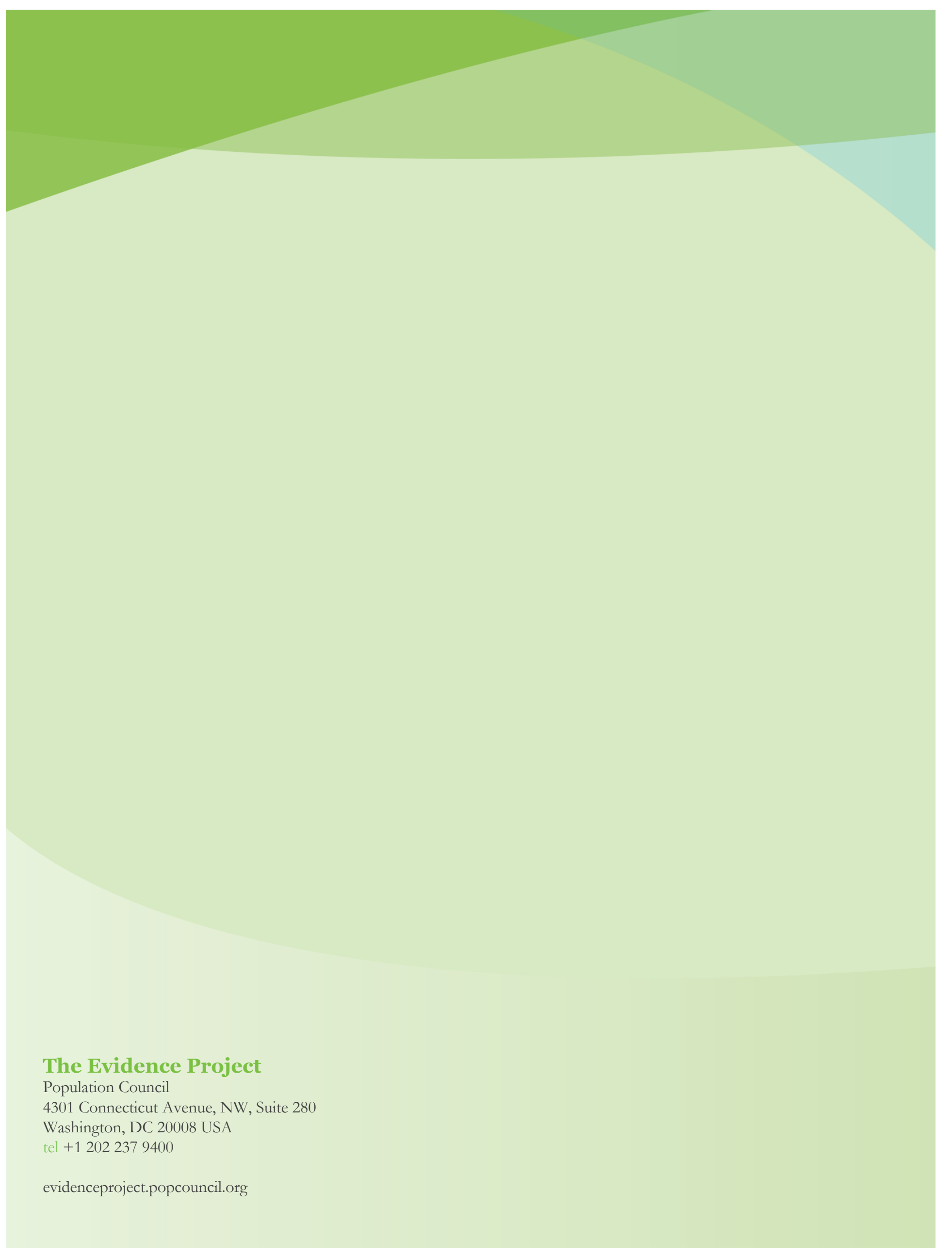

